\title{
Factors associated with relapse after ambulatory treatment of acute exacerbations of chronic bronchitis
}

\author{
M. Miravitlles*, C. Murio*, T. Guerrero\#, on behalf of the DAFNE Study Group
}

\begin{abstract}
Factors associated with relapse after ambulatory treatment of acute exacerbations of chronic bronchitis. M. Miravitlles, C. Murio, T. Guerrero, on behalf of the DAFNE Study Group. (C) ERS Journals Ltd 2001.

ABSTRACT: This study aimed to identify the risk factors for relapse after ambulatory treatment of acute exacerbations of chronic bronchitis (AECB) that can easily be used in a primary care setting.

Data were prospectively collected on 2,414 ambulatory patients with AECB from 268 general practices located throughout Spain. A multivariate model to identify risk factors independently associated with failures was developed and validated from the information recorded at the inclusion visit and at 30-days follow-up visit.

A total of 507 patients relapsed (21\%); of these, 84 required admission $(16.5 \%)$. The multivariate model for prediction of the risk of relapse included 2,414 cases: 1,689 for the developmental sample and 725 in the validation sample. The model obtained contained three readily-obtainable variables: ischaemic heart disease (odds ratio $(O R)=1.63 ; 95 \%$ confidence interval $(C I)=1.07-2.47)$, degree of dyspnoea $(\mathrm{OR}=1.31 ; 1.14-1.50)$ and number of visits to the general practitioner the previous year $(O R=1.07 ; 1.04-1.10)$. The model calibrated well in developmental and validation samples (goodness-of-fit tests: $p=0.295$ and $p=0.637$, respectively). Severity of the exacerbation was not associated with increased risk of relapse in either univariate or multivariate analysis.

The present results suggest that baseline characteristics of the patients such as degree of dyspnoea, coexisting ischaemic heart disease and number of previous visits to the general practitioner for respiratory problems are strongly associated with increased risk of relapse after ambulatory treatment of acute exacerbations of chronic bronchitis. In contrast, exacerbation severity was not associated with clinical failure. Guidelines for management of acute exacerbations of chronic bronchitis should consider such risk factors and advocate intensive broad spectrum treatment and closer follow-up of patients exhibiting them.

Eur Respir J 2001; 17: 928-933.
\end{abstract}

\begin{abstract}
*Dept of Pneumology, Vall d'Hebron General University Hospital, Barcelona, Spain and " Pharma Research, Division of Pharma Consult Services S.A., Barcelona, Spain.
\end{abstract}

Correspondence: M. Miravitlles, Rocafort 173-177, 08015 Barcelona, Spain. Fax: 34932746083

\section{Keywords: Chronic bronchitis comorbidity exacerbation \\ failure \\ primary care \\ treatment}

\section{Received: July 262000}

Accepted after revision December 1 2000

The DAFNE Group is funded by MERCK Farma y Química S.A.
A significant number of smokers will develop chronic cough and sputum production. The chronic and progressive course of the disease is often aggravated by short periods of increasing symptoms, particularly increasing cough, dyspnoea and production of sputum which can become purulent. The majority of these exacerbations are produced by bronchial infection and, if frequent, have been demonstrated to have a negative impact on quality of life in patients with chronic bronchial disease [1]. Furthermore, acute exacerbations are the most frequent cause of hospital admission and death among patients with chronic lung disease [2].

Most studies consistently show a failure rate of ambulatory treatment of exacerbations that ranges from $12-26 \%[3-6]$. Since relapse after initial treatment for acute exacerbation may lead to prolonged disability, a new course of antibiotics, an emergency visit or even hospital admission, it is crucial to identify patients most at risk for relapse. Identification of risk factors for failure of ambulatory treatment may permit the implementation of more aggressive broad spectrum treatment and closer follow-up. In a further step, risk factors associated with relapse should be incorporated into the management guidelines to aid general practitioners in identifying at-risk patients.

A cohort of patients with exacerbated chonic bronchitis was identified on a nationwide basis and was prospectively followed for 1 month to investigate the rate of failure and identify risk factors associated with relapse after ambulatory treatment of the exacerbation. This study's modelling goal was to develop and validate one simple system for estimating the probability of relapse after ambulatory treatment of an exacerbation of chronic bronchitis based on data collected in clinical records obtained at the visit to the general practitioner (GP). 


\section{Method}

\section{Study design}

This is a prospective study on ambulatory patients with exacerbated chronic bronchitis in a primary care setting. The study was conducted between December 1 , 1996 and April 30, 1997 in 268 general practices located throughout Spain and selected by regionally-stratified sampling. Information was sought on the first 10 unselected consecutive adults seen for exacerbated chronic bronchitis.

Diagnosis of chronic bronchitis was based on productive cough for at least 3 months in two consecutive yrs [7]. The degree of dyspnoea while in stable phase was used to classify the severity of the underlying disease and was assessed using the scale of MAHLER et al. [8]. Diagnosis of acute exacerbation was based on the presence of any combination of the following symptoms: increased dyspnoea, increased production and purulence of sputum which led to a change or increase in treatment. Severity of the exacerbation was classified using ANTHONISEN et al. [9] criteria: exacerbations presenting with any one of the previously mentioned symptoms were classified as type 3, those with two symptoms as type 2 , and those with all three symptoms as type 1. Exclusion criteria included diagnosed cystic fibrosis, asthma or severe bronchiectasis.

All information relevant to the study was collected by GPs at the time of the patient's medical visit. Since this was an observational study aimed at identifying current practice and real failure rates, not under experimental conditions, treatment of the exacerbation was left to the criteria of the attending physician. Patients were rescheduled to see their GP 1 month after the first visit in all cases, or as requested in case of persistence or increase in symptoms. Relapse was defined as an unscheduled visit to the GP before 1 month owing to persistence or increase in symptoms and which led to either a change in drug prescription, an emergency visit or an admission to hospital.

\section{Sample selection}

A regression model was constructed to identify variables independently and significantly associated with relapse. The model was constructed using a randomly-selected subsample of $70 \%$ of the subjects included (developmental model). The model obtained was tested with data derived from the remaining 30\% of the total population (validation sample). Developmental and validation samples were created by assigning each patient a random number between 0 and 1 . Patients with a random number of 0.70 or lower formed the developmental sample and the remaining patients formed the validation sample.

The aim of the model was to accurately reflect the relapse experience of the patient sample while containing the minimum number of variables necessary to calibrate and discriminate well in the developmental and validation samples. Only clearly definable and reliably obtained terms were included and the use of laboratory values, radiological examinations and measurements, which may not be performed as part of routine patient care, were avoided. Candidate variables to be included in the model were: age, sex, body mass index (BMI) calculated as $\mathrm{kg} \cdot \mathrm{m}^{-2}$, smoking habits (active smoker versus non- or exsmoker), presence or absence of chronic mucus hypersecretion ( $\mathrm{CMH})$ defined as emission of $>30 \mathrm{~mL}$ of sputum daily, and comorbidity $(0=$ no, $1=$ yes $)$ for any of the following: ischaemic heart disease, diabetes mellitus or hypertension, chosen by presenting a prevalence of $5 \%$ or greater of the study population, severity of the underlying disease quantified by the degree of dyspnoea, number of visits to the GP the previous year for respiratory symptoms, severity of the exacerbation based on classification as types 1,2 or 3, and treatment with oral steroids. Since all but 34 patients $(1.4 \%)$ received broad spectrum antibiotics, the use of antibiotics was not included as a variable in the model.

\section{Statistical analysis}

The association of categorical independent variables with failures was assessed by the Chi-squared test, and the significance of continuous variables was assessed with unpaired t-test and Wilcoxon's rank sum tests. Variables were eligible for entry into a multiple logistic regression model if they were significantly associated with failures at a $p$-value $<0.25$ and $\geqslant 5 \%$ of the population exhibited that factor. Correlations (r) among the regression coefficients were used to screen for multicollinearity [10]. Absolute values of $r>0.7$ were considered significant. The $\kappa$ statistic was used to assess inter-rater reliability of variables. Estimated coefficients and their SEMs were calculated using the method of maximum likelihood. Variables were eliminated from the model one at a time based on likelihood ratio tests.

When all statistically nonsignificant $(p>0.05)$ variables had been eliminated from the multivariate model, calibration was assessed using the HOSMER-LEMESHOW [11] goodness-of-fit test. This test evaluates the degree of correspondence between a model's estimated probability of failure and the actual failure rate of patients over groups spanning the entire range of probabilities.

Discrimination was assessed using the area under the receiver operating characteristic (ROC) curve [12] to evaluate how well the model distinguished patients who relapsed from patients who did not. The statistic represents, for all possible pairs of patients, the proportion in which the patient who relapsed had a higher probability of relapse than the patient who did not. All the data were analysed using the Statistical Analysis System (SAS) 6.04 (SAS Institute, Cary, NC, USA).

\section{Results}

Data were collected from 2,414 individuals with exacerbated chronic bronchitis. Characteristics of the patients are described in table 1 . Treatment administered for acute exacerbations included antibiotics in $98.6 \%$ and oral corticosteroids in $25 \%$ of cases. Coexisting respiratory medication included short-acting $\beta_{2}$-agonists in $56 \%$ of cases, inhaled 
Table 1.-Characteristics of the population included in the study and univariate analysis of variables possibly associated with relapse

\begin{tabular}{|c|c|c|c|c|}
\hline Variable & Total population & Success & Relapse & p-value \\
\hline Subjects $n$ & 2414 & 1907 & 507 & \\
\hline Males \% & 74.2 & 74.8 & 74.1 & 0.785 \\
\hline Age yrs & $67.1 \pm 10.3$ & $66.9 \pm 10.1$ & $68.1 \pm 10.2$ & 0.022 \\
\hline BMI $\mathrm{kg} \cdot \mathrm{m}^{-2}$ & $27.4 \pm 4.1$ & $27.3 \pm 4.0$ & $27.4 \pm 4.2$ & 0.388 \\
\hline Active smokers \% & $2 \overline{0.1}$ & $1 \overline{9} .9$ & $2 \overline{0} .7$ & 0.207 \\
\hline Pack-yrs & $41.7 \pm 27.0$ & $40.7 \pm 26.7$ & $43.1 \pm 25.8$ & 0.139 \\
\hline Exacerbations previous year & $3.0 \pm 2.2$ & $2.9 \pm 2.2$ & $3.4 \pm 2.1$ & $<0.0001$ \\
\hline Visits to the GP the previous year & $5.3 \pm 4.3$ & $4.9 \pm 3.8$ & $6.6 \pm 5.1$ & $<0.0001$ \\
\hline Evolution of the disease yrs & $12.6 \pm 8.2$ & $12.3 \pm 8.1$ & $13.9 \pm 8.5$ & 0.0007 \\
\hline СМH \% & 40.9 & 40.0 & $4 \overline{4} .1$ & 0.095 \\
\hline Hypertension \% & 34.1 & 33.6 & 35.7 & 0.391 \\
\hline Diabetes mellitus \% & 14.2 & 13.5 & 15.9 & 0.153 \\
\hline Ischaemic heart disease $\%$ & 8.5 & 7.1 & 11.8 & 0.002 \\
\hline \multicolumn{5}{|l|}{ Exacerbation \% } \\
\hline type 1 & 49.1 & 48.4 & 51.8 & 0.262 \\
\hline type 2 & 34.6 & 35.4 & 31.7 & \\
\hline type 3 & 16.2 & 16.1 & 16.5 & \\
\hline \multicolumn{5}{|l|}{ Dyspnoea $\%$} \\
\hline degree 0 & 9.0 & 10.0 & 5.4 & 0.001 \\
\hline degree I & 40.2 & 42.4 & 31.9 & \\
\hline degree II & 32.4 & 31.6 & 35.5 & \\
\hline degree III & 14.5 & 13.4 & 18.5 & \\
\hline degree IV & 3.8 & 2.5 & 8.6 & \\
\hline
\end{tabular}

Data are presented as percentages or mean \pm SD. BMI: body mass index; GP: general practitioner; CMH: chronic mucus hypersecretion. Exacerbation types and dyspnoea degrees are defined in [9] and [8], respectively.

corticosteroids in $46.7 \%$, long-acting $\beta_{2}$-agonists in $41.4 \%$, theophyllines in $43.5 \%$, mucolytic agents in $38.2 \%$, ipratropium bromide in $26.9 \%$ and home oxygen therapy in $11.3 \%$.

A total of 507 patients $(21 \%)$ suffered a relapse of the exacerbation; in 262 cases $(51.6 \%)$ the relapse was resolved with an unscheduled visit and a change of treatment, but in 161 cases $(31.7 \%)$ patients required attention in an emergency department and 84 (16.5\%) were finally admitted to hospital. Characteristics of patients who relapsed and those who did not are presented in table 1 .

\section{Multivariate model}

The total population was randomly divided into two samples: 1,689 individuals for the developmental sample and 725 for the validation sample. The overall rate of patients who relapsed was $21.0 \% ; 21.0 \%$ in the developmental sample and $21.0 \%$ in the validation sample. Results of bivariate analysis of independent variables are also shown in table 1 . Mean age was $68.1 \mathrm{yrs}$ among patients who relapsed and $66.9 \mathrm{yrs}$ among patients who did not. Number of exacerbations the previous year was 3.4 in those who relapsed and 2.9 in those who did not. Patients who relapsed had seen their GP more often the previous year (6.6 times versus 4.9) and more frequently had ischaemic heart disease $(11.8 \%$ versus $7.1 \%)$. Each of these variables was selected as showing a significant difference of $\geqslant 0.25$. Conversely, the severity of the exacerbation was not selected for incorporation into the model, since it failed to show a significant relationship with relapse in univariate analysis $(\mathrm{p}>0.25)$.
A significant correlation was observed between the number of exacerbations the previous year and the number of visits to the GP for respiratory problems (Spearman's $r=0.71 ; \mathrm{p}<0.0001$ ); thus, the number of visits to the GP was selected to enter the model. Similarly, the use of oral steroids correlated with disease severity, measured by the degree of dyspnoea at baseline $(r=0.82 ; \mathrm{p}<0.0001)$; since the use of corticosteroids is the consequence of the severity and not vice versa, the degree of dyspnoea was the variable chosen for the model.

Multiple logistic regression modelling in the developmental data set resulted in a model containing three variables. Table 2 presents the estimated logistic regression coefficients, estimated SEMs, adjusted odds ratios (ORs) and 95\% confidence intervals (CIs) for the adjusted ORs for the final model for relapse. The presence of ischaemic heart disease had an OR of 1.63, which signifies that a patient that had this condition would be 1.63 times as likely to relapse as another patient that did not have this disease. The degree of dyspnoea and the number of visits to the GP the previous year also had a significant association with relapse.

The Hosmer-LeMEshow [11] goodness-of-fit test indicated that the model was well calibrated $(p=$ 0.295). In this test, a high $\mathrm{p}$-value indicates that the model is performing well, which means that no large discrepancy is found between observed and expected rates of relapse. When the model was applied to the validation data, the area under the ROC curve was 0.633 and the p-value for the goodness-of-fit 0.637 , indicating that the model validated well, especially by demonstrating good calibration and acceptable discrimination. 
Table 2. - Variables in the model for relapse with their estimated coefficients $(\beta)$ standard errors of the mean (SEMS), adjusted odds ratios (ORs), and 95\% confidence intervals (Cl) for the adjusted ORs

\begin{tabular}{lcccr}
\hline Variable & $\beta$ & SEM & Estimated adjusted OR & $95 \%$ CI \\
\hline Constant & -2.2569 & 0.1498 & & \\
Degree of dyspnoea & 0.2722 & 0.0691 & 1.313 & $1.14-1.50$ \\
Ischaemic heart disease & 0.4898 & 0.2127 & 1.632 & $1.07-2.47$ \\
Visits to the GP the previous year & 0.0726 & 0.0148 & 1.076 & $1.04-1.10$ \\
\hline
\end{tabular}

GP: general practitioner.

\section{Discussion}

The present findings show that severity of the underlying disease, classified by the degree of baseline dyspnoea, number of visits to the GP the previous year and coexistence of ischemic heart disease, are factors independently associated with increasing risk of relapse after ambulatory treatment for acute exacerbations of chronic bronchitis (AECB). However, the severity of the present exacerbation did not influence prognosis. From these results it can be speculated that the patient's functional status is crucial for establishing the risk of relapse of respiratory symptoms.

To the authors' knowledge, this is the largest prospective study conducted in patients with AECB. This study aimed to identify failure rates in real circumstances, and not under experimental conditions such as those of clinical trials. Thus, the election of treatment was left to the criteria of the corresponding physician. The use of antibiotics was generalized and did not permit comparison of relapse rates between patients taking or not taking antibiotics. Moreover, the wide variety of broad spectrum antibiotics given, and the lack of random allocation to one or another, prevented any analysis of the effects of individual antibiotics on failure rate. Similarly, another Spanish survey in primary care showed that antibiotics were used in $89 \%$ of AECB, and second-line, broadspectrum antibiotics were extensively prescribed irrespective of the severity of either the underlying disease or the exacerbation [13]. Therefore, the potential confounding effect of different antibiotics on outcomes can reasonably be ruled out. The effect of antibiotic treatment on relapse is controversial. BALL et al. [3] and Dewan et al. [14] observed no effect of antibiotic treatment on the relapse rate of exacerbations; in contrast, baseline characteristics of the patients, similar to those found in the present study, such as the number of previous chest infections and history of cardiopulmonary disease, were the best predictors of return to the GP with a chest problem. However, when comparing first-line antibiotics, such as amoxicillin, with second-line agents, i.e. amoxicillinclavulanate, cephalosporins, macrolides or quinolones, some studies showed a significant improvement in outcome for the latter group [4, 15]. Moreover, in a different setting such as in randomized, double-blind studies, different outcomes have been observed in high-risk patients, and results suggested quinolones could be first-choice therapy for more severe patients [16]. Similarly, pharmacoeconomic studies have shown that oral cephalosporines such as cefixime could be a cost-effective option for ambulatory treatment of AECB in mild-to-moderate patients [17].

The present study found an association between the number of visits to the GP the previous year for respiratory problems and increased risk of relapse; the risk of failure increased by $7.6 \%$ for every extra visit to the GP. The number of visits and the number of previous exacerbations were strongly correlated, suggesting that most visits to the GP were due to exacerbation symptoms. The number of visits was included in the model, since this should be more discriminative by showing the number of exacerbations severe enough to force the patient to seek medical attention. Recent examples suggest that the number of previous exacerbations may not be a reliable marker of severity; as an example, in a prospective study, SEEMUNGaL et al. [1] in a prospective study found that almost half of the exacerbations recorded on daily diary cards were not reported to their physicians. Similarly, their results showed frequent past exacerbations to be one of the factors most strongly associated with recurrent exacerbations [1]. In two other studies, the number of previous exacerbations was a risk factor for relapse after ambulatory treatment for an AECB $[3,14]$. The high admission and relapse rates for previous visits were also a significant risk factor for predicting the probability of admission for decompensated lung disease in patients who attended an emergency unit [18]. These results, together with the present ones, suggest that there exists a subgroup of patients more prone to developing recurrent respiratory infections, even with the same degree of severity of the underlying disease.

The present study observed that the presence of coexisting diabetes or significant cardiac disease was associated with increased risk of relapse in univariate analysis. However, after multivariate analysis, only ischemic heart disease was still significant, with an increased risk of $63 \%$. Similarly, other studies found coexistent cardiopulmonary disease to be a risk factor for referral to hospital after treatment for an acute exacerbation [3, 15], and cardiac comorbidity was found to be among the best predictors of mortality in a cohort of chronic obstructive pulmonary disease (COPD) patients discharged after an acute exacerbation [19]. In a previous retrospective study [20], the presence of ischemic heart disease or cardiac insufficiency were observed to be strongly correlated with an increased risk of hospital admission for decompensated COPD, with an OR of 1.97 (95\% CI=1.24-3.14). Conversely, ADAMs et al. [15] did not observe any association between comorbidity and outcome in a hospital-based population of severe COPD patients (29\% with a forced expiratory volume in one second 
(FEV1) $<35 \%$ and $27 \%$ with oxygen therapy). These results suggest that cardiac comorbidity is a risk factor of poor outcome, particularly in mild-to-moderate patients; however, when the pulmonary disease is severe, the impairment in pulmonary function prevails over cardiac disease as a risk factor. Cardiac comorbidity may also provoke admission during exacerbations and even be a cause of death, particularly in elderly patients $[20,21]$.

Severity of the underlying disease is an important risk factor for relapse; patients with more severe dyspnoea at baseline were more at risk of returning to the GP with persistence or increase in symptoms. One possible explanation could be the demonstration that patients with more advanced bronchial disease are at increased risk of suffering exacerbations caused by bacteria more aggressive and resistant to antibiotics [22-24].

A limitation of the study is the subjective evaluation of severity based on the scale of baseline dyspnoea, instead of using objective measures of disability such as the FEV1 [25]. It must be considered that FEV1 is not readily available for most GPs in different countries. In Spain only $36 \%$ of GPs require pulmonary function tests in patients with obstructive lung disease [26, 27]. Similarly, in Canada, only $38 \%$ of GPs requested spirometry for chronic bronchitis patients [28]. Furthermore, quality of spirometry in the primary care setting is far from optimal and may yield conflicting results [29]. In this context, dyspnoea scales may be a reasonable and reliable measure of disability in patients with chronic obstructive lung disease [30]. It cannot be ruled out that some of the patients in the present study might have had asthma; however, a recent study in the UK observed that few asthmatics were mistakenly diagnosed as having COPD in primary care [31]. Based on the clinical characteristics of the present study's population, which are very similar to that of the aforementioned study [31], and having ever been diagnosed with asthma being an exclusion criterion, the authors do not believe that significant misdiagnosis of chronic bronchitis would have influenced the results.

Surprisingly, severity of the exacerbation did not influence outcome. However, severity of the disease was a determinant of outcome in placebo-controlled studies [9]. Since almost all patients in the present study were receiving broad-spectrum antibiotics, these results suggest that under broad-spectrum antimicrobial treatment, severity of symptoms of the exacerbation is no longer a risk factor for relapse. The present results, in a large cohort of patients, confirm the observations of previous studies $[3,14,15]$ that also failed to find any significant effect of exacerbation severity on outcome in smaller populations. Nevertheless, another possible marker of severity of the exacerbation, such as sputum colour, has been suggested as a useful marker of bacterial infection and the need for antibiotic treatment [32]; the prognostic value of this readilyobtainable marker must be validated in future prospective studies.

The model developed here for prediction of relapse after ambulatory treatment of acute exacerbations of chronic bronchitis indicates that a patient with ischaemic heart disease, degree III dyspnoea (Mahler's scale [8]) and who visited the general practitioner three times in the last year for respiratory problems has a relapse probability of $32.4 \%$, clearly higher than the mean $21 \%$ probability of the cohort. Considering the high prevalence of chronic bronchitis in the general population and the high number of medical consultations generated by this population, it is crucial to identify patients at risk for failure of treatment of exacerbations or at risk for repeated consultations for respiratory problems. Prospective studies, such as the present report, are useful for identifying and validating risk factors, some of which are already included in guidelines for management of patients with chronic bronchitis [33]. Patients exhibiting such factors should receive energetic treatment with broad-spectrum antibiotics, a short course of oral corticosteroids and should be closely followed-up in an attempt to avoid relapse which, in a significant number of cases, may lead to hospital admission or even be a cause of death.

\section{References}

1. Seemungal TAR, Donaldson GC, Paul EA, Bestall JC, Jeffries DJ, Wedzicha JA. Effect of exacerbation on quality of life in patients with chronic obstructive pulmonary disease. Am J Respir Crit Care Med 1998; 157: $1418-1422$.

2. Burrows B, Earle RH. Course and prognosis of chronic obstructive lung disease: a prospective study of 200 patients. N Engl J Med 1969; 280: 397-404.

3. Ball P, Harris JM, Lowson D, Tillotson G, Wilson R. Acute infective exacerbations of chronic bronchitis. $Q$ J Med 1995; 88: $61-68$.

4. Huchon GJ, Gialdroni-Grassi G, Léophonte P, Manresa F, Schaberg T, Woodhead M. Initial antibiotic therapy for lower respiratory tract infection in the community: a European survey. Eur Respir $J$ 1996; 9: $1590-1595$.

5. DeAbate CA, Henry D, Bensch G, et al. Sparfloxacin vs ofloxacin in the treatment of acute bacterial exacerbations of chronic bronchitis. A multicenter, double-blind, randomized, comparative study. Chest 1998; 114: $120-130$.

6. MacFarlane JT, Colville A, Guion A, MacFarlane RM, Rose DH. Prospective study of aetiology and outcome of adult lower respiratory tract infections in the community. Lancet 1993; 341: 511-514.

7. American Thoracic Society. Standards for the diagnosis and care of patients with chronic obstructive pulmonary disease. Am J Respir Crit Care Med 1995; 152: S77-S120.

8. Mahler DA, Weinberg DH, Wells CK, Feinstein AR. The measurement of dyspnea: contents, interobserver agreement, and physiologic correlates of two new clinical indexes. Chest 1984; 85: $751-758$.

9. Anthonisen NR, Manfreda J, Warren CPW, Hershfield ES, Harding GKM, Nelson NA. Antibiotic therapy in exacerbations of chronic obstructive pulmonary disease. Ann Intern Med 1987; 106 196-204.

10. Glantz SA, Slinker BK. Primer of Applied Regression and Analysis of Variance, New York, McGraw-Hill International Book Co., 1990; pp. 512-568. 
11. Hosmer DW, Lemeshow S. Applied logistic regression New York, John Wiley \& Sons Inc., 1989.

12. Hanley JA, McNeil BJ. The meaning and use of the area under a receiver operating characteristic (ROC) curve. Radiology 1982; 143: 29-36.

13. Miravitlles M, Mayordomo C, Artés M, SánchezAgudo L, Nicolau F, Segú JL on Behalf of the EOLO Group. Treatment of chronic obstructive pulmonary disease and its exacerbations in general practice. Respir Med 1999; 93: $173-179$.

14. Dewan NA, Rafique S, Kanwar B, et al. Acute exacerbation of COPD. Factors associated with poor outcome. Chest 2000; 117: 662-671.

15. Adams SG, Melo J, Luther M, Anzueto A. Antibiotics are associated with lower relapse rates in outpatients with acute exacerbations of COPD. Chest 2000; 117: $1345-1352$

16. Grossman R, Mukherjee J, Vaughan D, et al. A 1-year community-based health economic study of ciprofloxacin $v s$ usual antibiotic treatment in acute exacerbations of chronic bronchitis. Chest 1998; 113: $131-141$.

17. Miravitlles M, Segú Jl, Guerrero T, Gisbert R, Murio C (DAFNE Group). Pharmacoeconomic study of antibiotic treatment of acute exacerbations of chronic bronchitis in Primary Care. Aten Primaria (Barc) 2000; 25: $153-159$.

18. Murata GH, Gorby MS, Kapsner CO, Chick TW, Halperin AK. A multivariate model for predicting hospital admissions for patients with decompensated chronic obstructive pulmonary disease. Arch Intern Med 1992; 152: 82-86.

19. Antonelli Incalzi R, Fuso L, De Rosa M, et al. Co-morbidity contributes to predict mortality of patients with chronic obstructive pulmonary disease. Eur Respir J 1997; 10: 2794-2800.

20. Miravitlles M, Guerrero T, Mayordomo C, SánchezAgudo L, Nicolau F, Segú JL on Behalf of the EOLO Group. Factors associated with increased risk of exacerbation and hospital admission in a cohort of ambulatory COPD patients: a multiple logistic regression analysis. Respiration 2000; 67: $495-501$.

21. Vilkman S, Keistinen $\mathrm{T}$, Tuuponen $\mathrm{T}$, Kivelä SL. Survival and cause of death among elderly chronic obstructive pulmonary disease patients after first admission to hospital. Respiration 1997; 64: $281-284$

22. Eller J, Ede A, Schaberg T, Niederman MS, Mauch H, Lode H. Infective exacerbations of chronic bronchitis. Relation between bacteriologic etiology and lung function. Chest 1998; 113: $1542-1548$.

23. Miravitlles $M$, Espinosa $C$, Fernández-Laso E, Martos JA, Maldonado JA, Gallego M and Study Group of Bacterial Infection in COPD. Relationship between bacterial flora in sputum and functional impairment in patients with acute exacerbations of COPD. Chest 1999; 116: 40-46.

24. Sportel JH, Köter GH, van Altena R, Löwenberg A, Boersma WG. Relation between beta-lactamaseproducing bacteria and patient characteristics in chronic obstructive pulmonary disease (COPD). Thorax 1995; 50: 249-253.

25. Hansen EF, Phanareth K, Laursen LC, Kok-Jensen A, Dirksen A. Reversible and irreversible airflow obstruction as predictor of overall mortality in asthma and chronic obstructive pulmonary disease. Am J Respir Crit Care Med 1999; 159: 1267-1271.

26. Naberan Toña C. Survey about Barcelona health centre general practitioners' therapeutic attitude and control criteria of the patients with chronic respiratory disease. Aten Primaria (Barc) 1994; 13: 112-115.

27. Miravitlles M, Murio C, Guerrero T, Segú JL. Treatment of chronic bronchitis and COPD in primary care. Arch Bronconeumol 1999; 35: 173-178.

28. Kesten S, Chapman KR. Physician perceptions and management of COPD. Chest 1993; 104: 254-258.

29. Eaton T, Withy S, Garrett JE, Mercer J, Whitlock RML, Rea HH. Spirometry in primary care. The importance of quality assurance and the impact of spirometry workshops. Chest 1999; 116: 416-423.

30. Bestall JC, Paul EA, Garrod R, Garnham R, Jones PW, Wedzicha JA. Usefulness of the Medical Research Council (MRC) dyspnoea scale as a measure of disability in patients with chronic obstructive pulmonary disease. Thorax 1999; 54: $581-586$.

31. O'Brien C, Guest PJ, Hill SL, Stockley RA. Physiological and radiological characterisation of patients diagnosed with chronic obstructive pulmonary disease in primary care. Thorax 2000; 55: 635-642.

32. Stockley RA, O'Brien C, Pye A, Hill SL. Relationship of sputum color to nature and outpatient management of acute exacerbations of COPD. Chest 2000; 117: $1638-1645$.

33. Balter MS, Hyland RH, Low DE, et al. Recommendations on the management of chronic bronchitis. A practical guide for Canadian physicians. Can Med Ass J 1994; 151: Suppl., 7-23.

\section{Appendix}

Calculation of probability of relapse after ambulatory treatment of an exacerbation requires the steps following.

1. Compute the logit $\mathrm{g}(\mathrm{x})$ defined as:

$$
\mathrm{g}(\mathrm{x})=\beta_{0}+\beta_{1} \mathrm{x}_{1}+\beta_{2} \mathrm{x}_{2}+\ldots . \mathrm{b} \beta_{\mathrm{k}} \mathrm{x}_{\mathrm{k}}
$$

where $\beta_{0}$ is the constant and $\beta_{1} x_{1}$ is the estimated coefficient for the ith variable times the value of the ith variable, with $\mathrm{i}$ taking on the values from 1 to $\mathrm{k}$, and $\mathrm{k}$ being the number of variables in the model. Number of exacerbations suffered the previous year and degree of dyspnoea are entered as numbers, while ischemic heart disease takes the values of 0 or 1 , signifying the absence or presence, respectively.

2. Transform the logit into a probability through the following calculation:

$$
\mathrm{P}(\text { relapse })=\left[\mathrm{e}^{\mathrm{g}(\mathrm{x})} / 1+\mathrm{e}^{\mathrm{g}(\mathrm{x})}\right]
$$

For example, a patient with ischaemic heart disease and a degree of dyspnoea of III, who visited the general practitioner three times in the last year would have a probability of relapse after being treated for an acute exacerbation of:

$$
\begin{aligned}
\operatorname{logit} & =-2.2569+0.2722 \times 3+0.4898 \times 1+0.0726 \times 3 \\
& =-0.7327 ; \mathrm{e}^{-0.7327} / 1+\mathrm{e}^{-0.7327}=0.3246
\end{aligned}
$$

The probability of relapse is $32.4 \%$. This probability is an estimate, or expectation, based on the relapse rate of a large group of similar patients and represents the proportion of patients expected to exhibit the outcome. 